\title{
Thermal Cycling Behavior of Plasma Sprayed Segmented Thermal Barrier Coatings
}

\author{
Hongbo Guo*, Hideyuki Murakami and Seiji Kuroda \\ Thermal Spray Group, Materials Engineering Laboratory, National Institute for Materials Science, Tsukuba 305-0047, Japan
}

Thermal barrier coatings (TBCs) with different levels of segmentation crack densities $\left(D_{\mathrm{s}}\right)$ were sprayed at different substrate temperatures $\left(T_{\mathrm{s}}\right)$. Thermal cycling resistance of the TBC specimen was examined. The segmented coating significantly improved the thermal cycling resistance as compared to the traditional non-segmented coating. Maximum thermal cycling lifetimes were achieved in the coating with a crack density level of $2.2 \mathrm{~mm}^{-1}$. New segmentation cracks were hardly generated during thermal cycling testing. Spallation of segments within the segmented coating occurred, which is different from spallation of the whole coating from substrate in the case of traditional coating. Oxidation of bond coat and limited phase decomposition of YSZ topcoat were considered as not responsible for the failure of TBCs.

(Received October 27, 2005; Accepted January 19, 2006; Published February 15, 2006)

Keywords: thermal barrier coatings, plasma spray, segmentation cracks, thermal cycling, failure mechanism

\section{Introduction}

Turbine engine components are subjected to high thermal and mechanical loads. Ceramic thermal barrier coatings (TBCs) are used to protect the components from thermal loads by decreasing the surface temperature of the metallic substrate. Generally, plasma sprayed (PS) thermal barrier coatings (TBCs) have exhibited shorter thermal cycling lifetimes than electron beam physical vapor deposition (EBPVD) TBCs, which makes PS TBCs suitable only for less exacting applications in gas turbines. The failure of plasma sprayed TBCs is mainly caused by the sintering and the progressive destabilization of the zirconia topcoat, due to thermal mismatch stresses applied to the coating, and the formation of thermally grown oxide (TGO), as well as thermal shock.

Recently, it was reported that macrocracks in TBC perpendicular to a substrate, namely segmentation cracks, are beneficial to increase the thermal cycling lifetime of plasma sprayed TBCs, by accommodating the stresses arising from the different thermal expansions between the coating and substrate. ${ }^{1-3)}$ Such macrocracks can be developed by post treatment such as laser glazing, ${ }^{4,5)}$ or directly introduced during the deposition by applying high heat input to the substrate and high lamellar thickness. ${ }^{2,3,6)}$

The formation mechanism of segmentation cracks and thermo-physical properties of the segmented coatings have been investigated. ${ }^{7-9)}$ However, the thermal cycling behavior and associated failure mechanism of the segmented TBCs are seldom reported. In this paper, thick TBCs with different levels of segmentation crack densities $\left(D_{\mathrm{s}}\right)$ are produced by controlling the spray parameters. The thermal cycling behavior of traditional non-segmented and modified segmented TBCs is studied. The failure mechanisms of these TBCs are also discussed.

\section{Experimental}

Co-32Ni-21Cr-8Al-0.5Y powder (Sulzer Metco 9954) and $\mathrm{ZrO}_{2}-8$ mass $\% \quad \mathrm{Y}_{2} \mathrm{O}_{3}$ powder (Sulzer Metco 204 NS)

*Corresponding author, E-mail: Guo.hongbo@nims.go.jp
Table 1 Spray parameters for YSZ topcoat ( $V$ : traverse speed of plasma gun; $T_{\mathrm{s}}$ : substrate temperature during spraying).

\begin{tabular}{cccccccc}
\hline No. & $\begin{array}{c}\text { Power } \\
(\mathrm{KW})\end{array}$ & $\begin{array}{c}\mathrm{Ar} \\
(\mathrm{slpm})\end{array}$ & $\begin{array}{c}\mathrm{He} \\
(\mathrm{slpm})\end{array}$ & $\begin{array}{c}\text { Distance } \\
(\mathrm{mm})\end{array}$ & $\begin{array}{c}\text { Feed rate } \\
(\mathrm{g} / \mathrm{min})\end{array}$ & $\begin{array}{c}V \\
(\mathrm{~mm} / \mathrm{s})\end{array}$ & $\begin{array}{c}T_{\mathrm{s}} \\
(\mathrm{K})\end{array}$ \\
\hline $\mathrm{C} 1$ & 23.1 & 50 & 27 & 120 & 20 & 150 & 593 \\
$\mathrm{C} 2$ & 26.4 & 50 & 27 & 100 & 20 & 150 & 773 \\
$\mathrm{C} 3$ & 34 & 50 & 27 & 80 & 20 & 150 & 923 \\
$\mathrm{C} 4$ & 40.8 & 50 & 27 & 60 & 20 & 150 & 1073 \\
\hline
\end{tabular}

were used as spraying materials for MCrAlY bond coat and yttria stabilized zirconia (YSZ) topcoat, respectively. The MCrAlY bond coat was sprayed onto a Ni-based superalloy (Inconel 718) by low pressure plasma spray (Plasma Giken Corp., Japan). YSZ coatings were sprayed onto the bond coat in atmospheric plasma spraying using an SG 100 gun (Praxair, USA). The thicknesses of the sprayed MCrAlY bond coat and YSZ topcoat were in a range of 80-150 $\mu \mathrm{m}$ and around $800 \mu \mathrm{m}$, respectively. Four sets of spray parameters, as shown in Table 1, were used for spraying YSZ coatings aiming at attaining different levels of segmentation crack densities. The choice of spray parameters for spraying segmented TBCs is based on the experimental details described in some literatures. ${ }^{7,8}$ The main idea is that segmentation cracks were created by thermal tensile stresses during the deposition and hence, the heat input to the substrate should be enough high. ${ }^{9)}$ Regarding to this, the substrate temperatures were varied by controlling spray distance and power. Condition 1 (C1), featured with a lower plasma power and a long spray distance as compared to other spray conditions, was used for spraying traditional nonsegmented TBCs.

Thermal cycling testing of disk-shaped specimens $(\phi 25 \mathrm{~mm} \times 3 \mathrm{~mm})$ was performed in a high temperature furnace equipped with an automatic mechanical system to move 4 specimens in and out of the furnace simultaneously. Two furnace temperatures for the testing were selected: namely $1373 \mathrm{~K}$ (low temperature, LT) and $1473 \mathrm{~K}$ (high temperature, HT). The coating surface and substrate temperatures of the specimen were measured by thermocouples fixed to the specimen. The temperature history was monitored by a computer connected with the thermocouples. As 


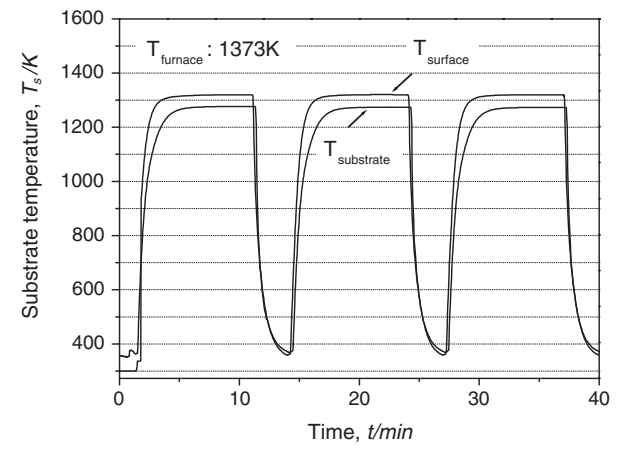

Fig. 1 Temperature history of TBC specimen during low temperature testing $\left(T_{\text {furnace }}=1373 \mathrm{~K}\right)$.

shown in Fig. 1, the specimen was heated to the maximum temperature for $10 \mathrm{~min}$ and then cooled by air jets for $3 \mathrm{~min}$ from both the coating and substrate sides. For the HT condition, the maximum coating surface and substrate temperatures were measured to be around 1393 and 1313 $\mathrm{K}$, respectively. For the LT condition, the coating surface and substrate temperatures were 1323 and $1273 \mathrm{~K}$, respectively. The lifetime of a TBC specimen is defined as the number of cycles the specimen underwent before more than $1 / 3$ surface area of the coating spalled off from the substrate.

The microstructures of the coatings before and after thermal cycling testing were examined by optical microscopy (OM), scanning electron microscopy (SEM), and the phases in the YSZ coatings examined by X-ray diffractometry (XRD).

\section{Results and Discussion}

\subsection{Microstructures}

Figure 2 shows the cross-sections of the as-sprayed coatings. The coating sprayed at $\mathrm{C} 1$ is characterized by a highly porous microstructure as shown in Fig. 2(a). In contrast to the coating (a), the coating (b) sprayed at $\mathrm{C} 4$ is much denser and contains some segmentation cracks (marked by white arrows) which run perpendicular to the coating plane and have penetrated at least half the coating thickness, as shown in Fig. 2(b). Such cracks initiate during the deposition phase, as a result of stress relaxation when the coating was subjected to bi-axial tensile stress. ${ }^{9)}$ The effects of spray conditions on the development of segmentation cracks have been discussed in detail elsewhere. ${ }^{7,8)}$ It should be noted that most of these segmentation cracks could not extend to the bottom of the coating. As a result, there is a non-segmented area in the YSZ topcoat close to its interface with the bond coat. In addition, the spray conditions also affect other coating microstructures. A lower porosity was achieved in the coating sprayed at high plasma power and short spray distance (i.e. C4), which is mainly attributed to the decreased volume of microcracks due to the improved intersplat contact at high temperature. ${ }^{7,10)}$

Segmentation crack density $\left(D_{\mathrm{s}}\right)$ of the TBCs before and after cycling testing was measured. In this study, $D_{\mathrm{s}}$ is defined as the number of segmentation cracks per unit horizontal length in a cross section examined. The $D_{\text {s }}$ values show a strong dependence on the substrate temperature measured during the spraying of each coating, as shown in
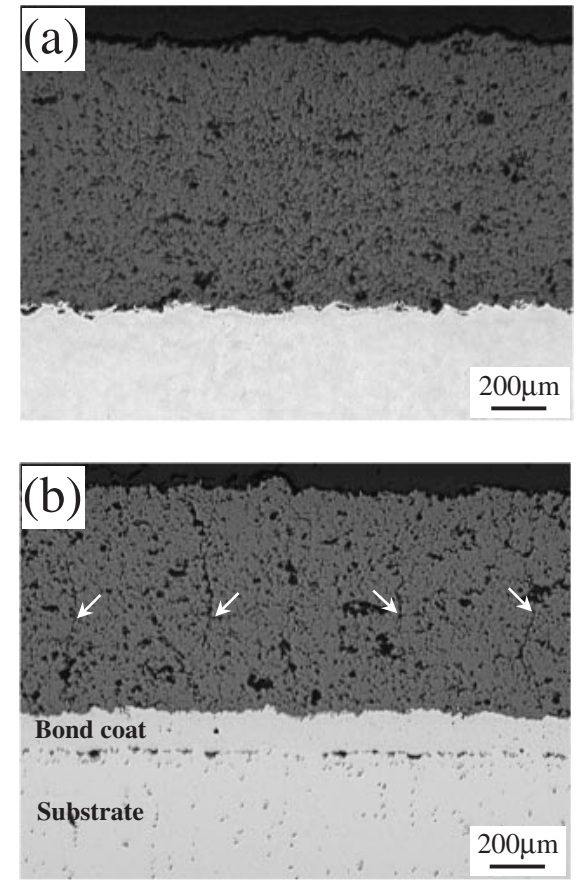

Fig. 2 Cross-sections of traditional non-segmented TBC sprayed at C1 (a) and highly segmented TBC sprayed at C4 (b).

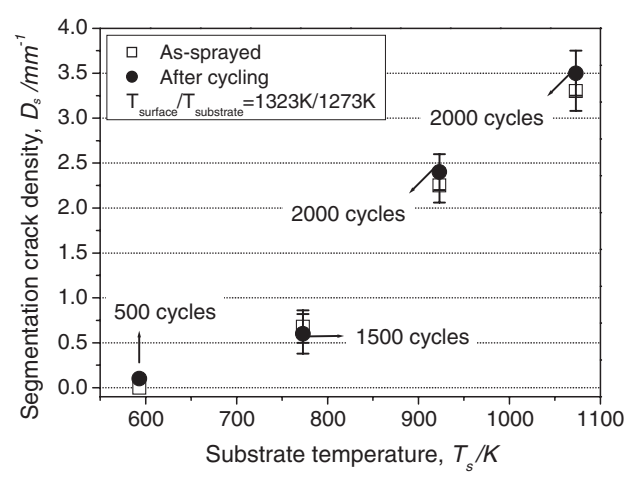

Fig. 3 Segmentation crack density $\left(D_{\mathrm{s}}\right)$ of YSZ coating $(\mathrm{C} 4)$ before and after thermal cycling test ( $\left.T_{\text {surface }} / T_{\text {substrate }}: 1323 \mathrm{~K} / 1273 \mathrm{~K}\right)$.

Fig. 3. A high $D_{\mathrm{s}}$ value of $3 \mathrm{~mm}^{-1}$ was achieved in the coating sprayed at $1073 \mathrm{~K}$. For the coating sprayed at $593 \mathrm{~K}$, $D_{\text {s }}$ was nearly zero, indicating that it is a traditional nonsegmented coating. The crack densities for the coatings after LT testing were slightly different from those before testing, however, the difference was not significant considering the uncertainty associated with the measurements. So, it can be concluded that no additional segmentation cracks were created due to the thermal cycling test.

\subsection{Thermal cycling lifetimes}

Figure 4 shows the dependence of lifetimes of TBC specimens on $D_{\mathrm{s}}$. In the case of LT testing, the traditional (non-segmented) specimen survived a lifetime of about 650 cycles, while the specimen failed after only few cycles in the HT testing. In all cases, the segmented TBCs showed a significant improvement in the lifetime as compared to the traditional coating. Particularly, the coating sprayed at C3 exhibited lifetimes of more than 2000 cycles in the LT testing 


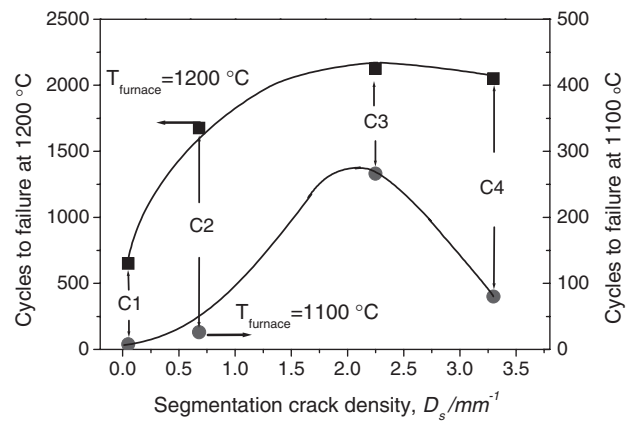

Fig. 4 Lifetimes of TBC specimens.

and 250 cycles in the HT testing. This indicates that segmentation cracks have a strong impact of prolonging the lifetimes of TBCs. It should be noted also that the lifetime of TBC specimens did not always increase with increasing $D_{\mathrm{s}}$. As shown in Fig. 4, the maximum value of lifetime was achieved in the coating with a crack density level of around $2.2 \mathrm{~mm}^{-1}$; the coating lifetime could not be effectively improved by further increasing $D_{\mathrm{s}}$ to $3.3 \mathrm{~mm}^{-1}$. Therefore, it can be considered that there is an optimum level of $D_{\mathrm{s}}$ for the thermal cycling lifetime of TBC above which the lifetime cannot be improved further.

Segmentation cracks are introduced into the TBCs during deposition due to the relaxation of thermal tensile stresses. High heat input to a substrate is necessary for the initiation and propagation of the cracks. High substrate temperature and thick lamellar thickness usually give rise to a high segmentation crack density. ${ }^{10)}$ In the present work, the substrate temperature during spraying went up even to $1073 \mathrm{~K}$ in order to produce highly segmented coatings. In such case, however, the bond coat on the substrate could be oxidized during spraying, which then would reduce the bond strength between the TBC and the bond coat. Therefore, it is possible that the coatings sprayed at the extremely high temperature failed earlier than those sprayed at a moderate temperature because of the bond coat oxidation during the deposition of TBC.

\subsection{Failure mechanisms}

Figure 5 shows the failure modes of the TBC specimens after LT testing. The non-segmented specimen was completely spalled off from the substrate after around 650 cycles by cracking at the interface between the YSZ topcoat and the bond coat. This is a typical failure mechanism of plasma sprayed TBCs caused by thermal stresses arising from the different thermal expansions between the topcoat and bond coat. For the highly segmented specimen after 2050 cycle testing, a large horizontal crack initiated from the edge of the specimen and propagated along the interface from the edge towards the center. Due to this, some of segments within the TBC were already spalled. Also, some chippings from the surface of the topcoat can be observed. Therefore, it is clear that the failure of the segmented coating started from the edge of the specimen and proceeded towards the center. Due to the propagation of horizontal cracks as shown in Fig. 5(b), only some segments within the coating rather than the whole coating were spalled from the substrate.
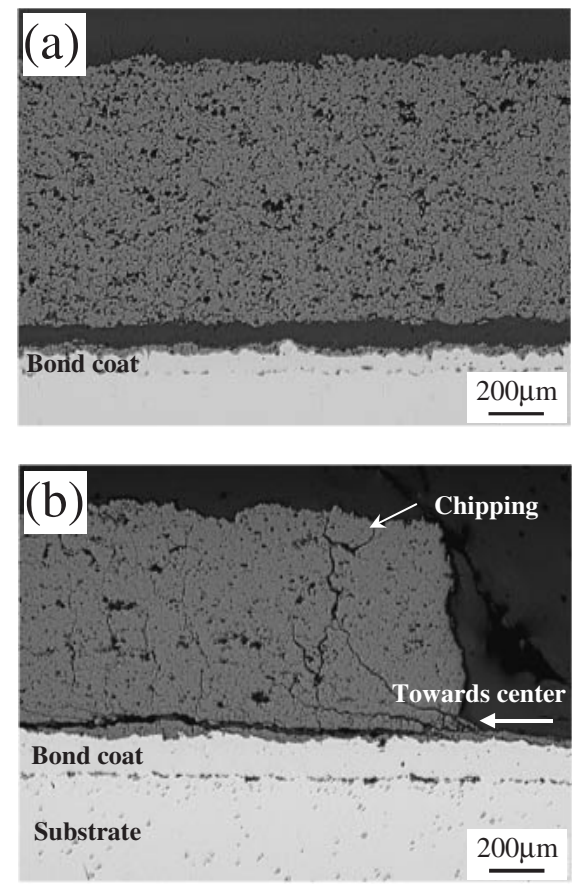

Fig. 5 Cross-sections of TBC specimens after thermal cycling ( $T_{\text {surface }} /$ $T_{\text {substrate }}: 1323 \mathrm{~K} / 1273 \mathrm{~K}$ ). (a) Traditional non-segmented $(\mathrm{C} 1), 650$ cycles; (b) Highly segmented (C4), 2050 cycles.

The results of the thermal cycling tests shows that the segmented TBC significantly improved the thermal cycling lifetimes as compared to the traditional TBC. Furthermore, the segmented coating exhibited a different failure mechanism from the traditional one. These can be explained by the presence of segmentation crack network in the TBC. Such cracks should be able to improve the strain tolerance of the coatings by opening the crack spacing during tensile loading and closing during compressive loading, which is similar to the behavior of inter-column gaps of EB-PVD coatings. The strain tolerance may be explained as a reduction of stress concentration at the various edges existing in a TBC coated specimen. More specifically, at free edges such as at the rim of a disk specimen and around the periphery of each segment within the segmented coating, shear stresses at the interface between coating and substrate will develop because of the different thermal expansions between the materials, which might place $\mathrm{TBC}$ in lateral tension on compression depending on the instantaneous temperature as well as the specimen's thermal history. The geometrical factors to determine the magnitude of the maximum shear stresses at the edges should be the coating thickness and the area of each coating segment. Assuming a constant TBC thickness, small coating segment area should lead to smaller stresses. Therefore, it is reasonable to expect smaller shear stresses being generated in a highly segmented specimen as compared to a non-segmented specimen, and hence the driving force to produce an interface crack is significantly reduced.

Although there are several other possible factors which affect thermal properties of TBCs, such as porosity and other horizontal cracks, it is found in this study that the segmentation cracks play a dominant role in improving the lifetimes of TBCs. A couple of factors related to the 


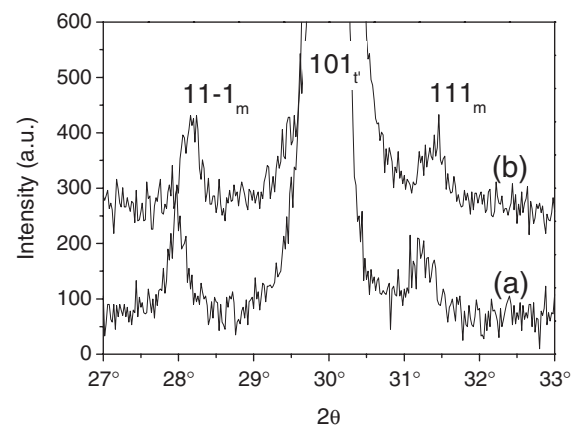

Fig. 6 XRD profiles of YSZ top coats before thermal cycling (a) and after 2050 cycles to $1323 \mathrm{~K}$.

changes in the materials microstructure need to be further considered.

Plasma sprayed 8YSZ coatings mostly consist of a nonequilibrium tetragonal phase (denoted as $\mathrm{t}^{\prime}$ ) due to the rapid cooling of the coating during the spraying process. Nevertheless, decomposition of $\mathrm{t}^{\prime}$ phase occurs during high temperature exposure. The $\mathrm{t}^{\prime}$ phase first transforms to the stable tetragonal phase $(\mathrm{t})$ with low yttria content during the high temperature stage and then to the monoclinic phase (m) during cooling to room temperature. The phase transformation of $\mathrm{t}^{\prime}$ to $\mathrm{m}$ is associated with a volume expansion of up to $5 \%$. The volume expansion will deteriorate the integrity of YSZ topcoat and could hence cause the failure of TBCs. The phase stability of YSZ coatings are examined by XRD. Small amount of monoclinic phase are detected in both the assprayed coating and the coating after 2050 cycles to $1323 \mathrm{~K}$, as shown in Fig. 6. The presence of the monoclinic phase in the as-sprayed coating could be attributed to the special spraying condition for producing highly segmented coatings. As shown in Table 1, the substrate temperature (C4) was as high as $1073 \mathrm{~K}$. It can be inferred that the coating surface temperature should have been much higher than the substrate temperature during spraying. So, it is possible that the phase transformation of $\mathrm{t}$ to $\mathrm{m}$ occurred in the as-sprayed coating. As for the thermally cycled specimen, the maximum temperature it could be exposed to is lower than $1373 \mathrm{~K}$ (furnace temperature). And the total time of exposure to such high temperature was about $300 \mathrm{~h}$. It has been disclosed that the decomposition of the $\mathrm{t}^{\prime}$ phase is very slow at temperature below $1673 \mathrm{~K}$, for zirconia stabilized with 8 mass $\%$ yttria. ${ }^{11)}$ Therefore, it can be concluded that the limited phase decomposition as evidenced in the present study could not cause severe damage to the integrity of the TBC system.

Figure 7 shows a higher magnification of the cross-section of the TBC as shown in Fig. 5(b). It is evident that a TGO layer of about $5 \mu \mathrm{m}$ thickness was formed on the bond coat and some horizontal cracks (marked by black arrows) were developed in the YSZ topcoat closed to the TGO. However, since such cracks did not cause large delamination cracking as shown in Fig. 5, the oxidation of bond coat cannot be considered as the major reason for causing the failure.

With the qualitative analysis given so far, we presently believe that the geometrical effects of reducing stresses by segmentation cracks are playing the predominant role in prolonging the thermal cycling lifetime of TBCs, but more

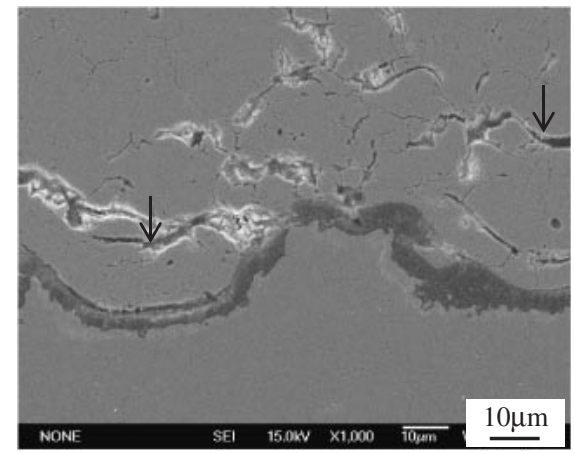

Fig. 7 SEM micrograph of cross-section of the TBC (C4) after 2050 cycles at low temperature testing, showing the formation of TGO on the bond coat.

quantitative analysis should be carried out in the near future.

\section{Conclusion}

Thick thermal barrier coatings with different levels of segmentation crack densities $\left(D_{\mathrm{s}}\right)$ have been sprayed by controlling the heat input to substrate. The TBC with a crack density level of $2.2 \mathrm{~mm}^{-1}$ exhibited a thermal cycling lifetime of more than 2000 cycles in LT testing and of 250 cycles in HT testing, indicating a significant improvement in thermal cycling resistance as compared to the traditional nonsegmented TBC. Failure of the segmented coating occurred by spallation of segments within the coating due to the propagation of interface cracks from the periphery towards the center of specimen, which is different from spallation of the whole coating from substrate in the case of traditional coating. Oxidation of bond coat and limited phase decomposition of YSZ topcoat were not the major reason for causing the failure. No new segmentation cracks were generated during thermal cycling testing.

\section{Acknowledgement}

This work is supported by Japan society for the promotion of science (JSPS) Fellowship program.

\section{REFERENCES}

1) T. A. Taylor, D. L. Appleby, A. E. Weatherill and J. Griffiths: Surf. Coat. Technol. 43/44 (1990) 470-480.

2) P. Bengtsson, T. Ericsson and J. Wigren: J. Therm. Spray Technol. 7 (1998) 340-348.

3) H. B. Guo, R. Vaßen and D. Stöver: Surf. Coat. Technol. 192 (2005) 48-56.

4) S. Ahmaniemi, P. Vuoristo, T. Mäntylä, G. Gualco, A. Bonadei and R. Di Maggio: Surf. Coat. Technol. 190 (2005) 378-387.

5) H. L. Tsai and P. C. Tsai: Surf. Coat. Technol. 71 (1995) 53-59.

6) H. B. Guo, H. Murakami and S. Kuroda: Mater. Trans. 46 (2005) 17751778.

7) H. B. Guo, R. Vaßen and D. Stöver: Surf. Coat. Technol. 186 (2004) 353-363.

8) H. B. Guo, S. Kuroda and H. Murakami: Thin Solid Films (2006) in press.

9) S. Kuroda and T. W. Clyne: Thin Solid Films 200 (1991) 49-66.

10) H. B. Guo, S. Kuroda and H. Murakami: J. Am. Ceram. Soc. accepted.

11) J. R. Brandon and R. Taylor: Surf. Coat. Technol. 46 (1991) 75-90. 